\title{
O gênero Swartzia Schreb. (Leguminosae, Papilionoideae) NO ESTADO do Rio DE JANEIRO
}

\author{
Vidal de Freitas Mansano ${ }^{1,2}$ \& Jacira Rabelo Lima ${ }^{1}$
}

\section{Resumo}

(O gênero Swartzia Schreb. (Leguminosae, Papilionoideae) no estado do Rio de Janeiro) Este trabalho consiste do levantamento dos táxons de Swartzia ocorrentes no estado do Rio de Janeiro. Os táxons encontrados no Rio de Janeiro são: Swartzia apetala var. apetala, S. apetala var. glabra, S. glazioviana, S. langsdorffii, S. myrtifolia var. elegans, S. oblata, S. pilulifera, S. simplex var. continentalis, S. simplex var. grandiflora e $S$. submarginata var. submarginata. São apresentadas chave de identificação, descrições, ilustrações, mapas de distribuição geográfica e ainda informações sobre os ambientes preferenciais para cada um dos 10 táxons encontrados no estado.

Palavras-chave: Taxonomia, flora, Swartzieae, Brasil.

\section{Abstract}

(The genus Swartzia Schreb. (Leguminosae, Papilionoideae) in the state of Rio de Janeiro) The taxa of Swartzia occurring in the state of Rio de Janeiro are: Swartzia apetala var. apetala, S. apetala var. glabra, S. glazioviana, S. langsdorffii, S. myrtifolia var. elegans, S. oblata, S. pilulifera, S. simplex var. grandiflora, S. simplex var. continentalis, and S. submarginata var. submarginata. Identification key, descriptions, illustrations, geographical distribution maps and also preferred habitats for each of the 10 taxa found in the state are presented.

Key words: Taxonomy, flora, Swartzieae, Brazil.

\section{INTRODUÇÃo}

Swartzia Schreb. é um gênero neotropical, pertencente à tribo Swartzieae, com cerca de 140 espécies (ca. 200 para Torke 2007) que foi revisado por Cowan (1968). A posição da tribo Swartzieae dentro de Leguminosae é controversa, mas atualmente Swartzia está incluído na subfamília Papilionoideae (Doyle et al. 1997; Herendeen 1995; Pennington et al. 2001; Polhill 1981).

O gênero apresenta uma estrutura floral peculiar, onde o cálice é inteiro no botão floral e se rompe irregularmente na antese, a corola apresenta uma pétala ou a pétala é ausente e $\mathrm{o}$ androceu é, geralmente, multiestaminado e heteromórfico, com até três tipos diferentes de estames (Mansano \& Souza 2005).

Desde a revisão do gênero (Cowan 1968), tem se observado um grande crescimento das coleções de herbário das regiões de florestas neotropicais e isto proporcionou análises mais detalhadas da variação morfológica em Swartzia. Em alguns casos, foi possível identificar descontinuidades de caracteres morfológicos em Swartzia, como pode ser verificado no antigo complexo Swartzia acutifolia por Mansano \& Tozzi (1999). Isto resultou em muitas propostas de novos táxons para o grupo e ainda em mudanças nomenclaturais.

O próprio Cowan $(1981,1985)$ descreveu seis espécies novas, sendo que cinco delas foram encontradas no Brasil e uma no Equador. Barneby $(1991,1992)$ descreveu outras cinco espécies ocorrentes na Venezuela e uma no Brasil, no estado do Pará. Outras duas espécies novas foram descritas para a região amazônica por Pipoly \& Rudas (1994), mais duas por Torke (2004) e uma por Mansano \& Souza (2005). Mansano \& Tozzi (1999, 2001) descreveram três espécies novas para a Região Sudeste do Brasil, propondo também delimitações de algumas espécies. Estes fatos mostram a necessidade de estudos regionais

Artigo recebido em 12/2006. Aceito para publicação em 03/2007.

${ }^{1}$ Instituto de Pesquisas Jardim Botânico do Rio de Janeiro, Rua Pacheco Leão 915, 22460-030, Rio de Janeiro, RJ, Brasil.

${ }^{2}$ Autor para correspondência: vidal@ jbrj.gov.br 
mais detalhados para o gênero, uma vez que a revisão do mesmo data quase 40 anos.

O estado do Rio de Janeiro, devido a sua localização e a grande diversidade de formações geológicas, caracteriza-se por apresentar uma significativa diversidade biológica e um alto grau de endemismo, demonstrando assim a importância da sua flora e fauna (Mori 1989; Peixoto 1991/92). O estado é considerado como centro de diversidade para espécies da mata atlântica (Projeto Flora do estado do Rio de Janeiro 2002 apud Costa et al. 2005), com endemismos inclusive para o gênero Swartzia (Cowan 1968, Mansano 1997).

Este trabalho teve como objetivos realizar o levantamento e a identificação das espécies de Swartzia ocorrentes no estado do Rio de Janeiro, a confecção de chave de identificação e a apresentação de descrições e ilustrações acompanhadas de dados sobre o ambiente preferencial destes táxons.

\section{Material e Métodos}

O material para a realização deste trabalho foi proveniente dos seguintes herbários: $\mathrm{BHCB}$, C, CVRD, ESA, ESAL, G, GUA, HRCB, HXBH, IAC, K, NY, PI, R, RB, SP, SPF, UEC, US e VIC (siglas designativas de acordo com Holmgren \& Holmgren 1998). As descrições são baseadas nas coleções do estado do Rio de Janeiro e as informações de distribuição e habitat são baseadas nos trabalhos de Mansano (1997) e Mansano \& Tozzi (1999, 2001). As palavras altura, comprimento, largura, diâmetro foram suprimidas das descrições quando óbvias. Os mapas de distribuição das espécies foram feitos utilizando o modelo disponível no site (http://splink.cria.org.br/mapper?criaLANG=pt) do Centro de Referência em Informação Ambiental (CRIA).

\section{Resultados e Discussão}

Swartzia Schreb., Gen. pl. 2: 518. 1791. Nom. cons.

Árvores ou arbustos. Folhas com 1 a vários folíolos, imparipinadas; estípulas caducas a persistentes; pecíolo e raque canaliculados, cilíndricos, marginados ou alados, freqüentemente estipelados; folíolos opostos, peciolulados, o par basal menor. Racemo, panícula ou fascículo de racemos, no caule, em ramos áfilos, nas axilas ou nas extremidades; brácteas presentes; bractéolas ausentes ou inseridas no pedicelo; botões globosos, elípticos ou ovados. Flor com hipanto ausente; cálice com 2-5 lobos após a antese, glabros internamente (lanoso em $S$. glazioviana); corola ausente ou com 1 pétala, caduca (exceto em S. langsdorffii, que é persistente por mais tempo que os estames); estames dimórficos, maiores 2-11, menores ca. 100, anteras dorsifixas; gineceu 1-pistilado, estipe conspícuo, ovário oval a fusiforme, estilete terminal ou lateral, estigma punctiforme a capitado. Fruto geralmente legume ou legume nucóide com 1 a 15 sementes, oval, moniliforme a achatado, sementes ariladas ou não.

Foram encontrados 10 táxons de Swartzia para o estado do Rio de Janeiro.

\section{Chave para a identificação dos táxons de Swartzia ocorrentes no estado do Rio de Janeiro}

1. Flores petalíferas.

2. Inflorescências axilares ou terminais (nunca em ramos áfilos); fruto do tipo legume com sementes pretas e arilo branco.

3. Folíolos 1-3; estames maiores 6-11, anteras ca. $4 \times 2 \mathrm{~mm}$; ovário 2-3 mm larg.

4. Folíolos 3; tronco cinza .

7.1. S. simplex var. grandiflora

4. Folíolo 1; tronco preto 7.2. S. simplex var. continentalis

3. Folíolos 5 ou mais; estames maiores 4-8, anteras 1,8-3,1 $\times 0,9-1,5 \mathrm{~mm}$; ovário 1-1,5 mm larg. 4.1. S. myrtifolia var. elegans 
2. Inflorescências em ramos áfilos, às vezes axilares; fruto geralmente legume nucóide com sementes beges a esverdeadas e arilo amarelo ou ausente.

5. Botões glabros; pétala com lâmina com 3-4 cm compr., persistente por mais tempo que os estames 3. S. langsdorffii

5. Botões indumentados; pétala com lâmina menor que $2 \mathrm{~cm}$ compr., caducas juntamente com os estames.

6. Cálice lanoso internamente 2. S. glazioviana

6. Cálice glabro internamente 7

7. Gineceu glabro

7. Gineceu seríceo 8. S. submarginata var. submarginata 1. Flores apétalas.

8. Ovário glabro 5. S. oblata

9. Pedicelo $2-8 \mathrm{~mm}$ compr., ovário com estipe até $3,5 \mathrm{~mm}$ compr.; gineceu preto quando seco 1.1. S. apetala var. apetala

9. Pedicelo 12-30 mm compr., ovário com estipe 4,5-7,5 mm compr.; gineceu verde ou bege-esverdeado quando seco 1.2. S. apetala var. glabra

8. Ovário lanoso 6. S. pilulifera

1. Swartzia apetala Raddi, Mem. Mat. Fis. Soc. ital. Sci. Moderna 18(2): 398. 1820.

Árvore 2,5-20 m; ramos estrigosos a glabros. Folha com estípulas $(1,8-) 3,5-8 \times$ $(0,4-) 0,6-1 \mathrm{~mm}$, persistentes, lanceoladas, glabras a estrigosas; pecíolo $(0,5-) 1,5-5(-10)$ $\mathrm{cm}$, estreitamente alado a marginado, asa ca. $3 \mathrm{~mm}$ larg., canaliculado glabro a pubérulo; raque $2,5-18 \mathrm{~cm}$, alada a marginada, asa até $2 \mathrm{~mm}$ larg., canaliculada, glabra a estrigosa; peciólulo 1,3-4 $\mathrm{mm}$, glabro a pubéruloestrigoso; folíolos 3-11, 4-11(-14) × 1,6-5 cm, elípticos a ovados, os basais menores, cartáceos a coriáceos, glabros a pilosos na face adaxial, pilosos na face abaxial, base assimétrica aguda a cordada, ápice acuminado a obtuso, nervura central proeminente na face abaxial e sulcada na adaxial. Racemos, panículas ou fascículos de racemos, 3,6-18,4 cm, axilares ou caulifloros, eixo glabro a pubérulo; brácteas $0,3-2 \times 0,08-1 \mathrm{~mm}$, persistentes, triangulares a lanceoladas, glabras a pubérulas; bractéolas ausentes; pedicelo $0,2-3 \mathrm{~cm}$, glabro a pubérulo; botões 2,9-6,5 × 3,5-5 mm, globosos a ovais, glabros. Flor com cálice 3-4lobado, lobos irregulares, glabros internamente; pétala ausente; estames amarelos, maiores $2-4$, filetes $2,5-8,5 \times 0,3-0,6 \mathrm{~mm}$, glabros, anteras $0,7-2,5 \times 0,3-1,2 \mathrm{~mm}$, oblongo-ovais, estames menores, filetes $2-8 \mathrm{~mm}$, glabros, anteras obladas, $0,6-1 \times 0,7-1 \mathrm{~mm}$, glabras; gineceu glabro, estipe 2,6-7,5 mm, ovário 2-5,5 $\times 0,9-2,3 \mathrm{~mm}$, elíptico a obovado, ca. 7-ovulado, estilete $0,3-1,5 \mathrm{~mm}$, lateral, estigma punctiforme. Legume 1,5-3 × 0,7-2 cm, ovóide a globoso, 1-seminado, glabro, áspero, alaranjado, sementes pretas, arilo branco.

Este táxon é representado por duas variedades no estado do Rio de Janeiro: Swartzia apetala var. apetala e $S$. apetala var. glabra.

\subsection{Swartzia apetala Raddi var. apetala}

Figs. 1 (a-c) e 2

Pedicelo 2-8 $\mathrm{mm}$; gineceu preto no material herborizado, estipe até $3,5 \mathrm{~mm}$.

Material selecionado: BRASIL. RIO DE JANEIRO: Araruama, Ibicuiba, estrada para Engenho Grande, 29.IV.2004, H. C. Lima 6185 (RB); Búzios, Reserva Taúa, 17.V.2005, R. D. Ribeiro 466 (RB); Cabo Frio, Tamoios, Reserva Ecológica do Mico Leão Dourado, 28.IX.2003, R. D. Ribeiro 18 (RB); Maricá, Barra de Maricá, 14.III.1982, G. P. Lewis 1189 (NY, RB); idem, Restinga da Barra, 8.VIII.1984, D. Araújo 6346 (GUA, NY); Paraíba do Sul, 27.VII.2004, $R$. Marquete 3519 (RB); idem, 22.XI.1936, M. Kuhlmann s.n. (NY); Praia Grande, 27.III.1877, A. F. M. Glaziou 8622 (R); Rio de Janeiro, 16.I.1922, J. G. Kuhlmann s.n. (NY 1441932); idem, Horto Florestal da Gávea, s.d., C. A. Lage s.n. (NY 2369063); São 
Gonçalo, Morro de Itaoca, 12.VII.1997, R. N. Damasceno 560 (RB); Saquarema, Restinga de Ipitangas, 23.XII.1986, H. C. Lima 2802 (NY, RB).

Ocorre em Alagoas, Bahia, Espírito Santo, porção leste de Minas Gerais até o Rio de Janeiro, onde foi encontrada principalmente na região litorânea, em áreas de mata e de restinga.

Coletada com flores praticamente durante o ano todo e com frutos principalmente entre os meses de maio a julho.

1.2 Swartzia apetala var. glabra (Vogel) R.S. Cowan, Fl. Neotrop. Monogr. 1: 156. 1968.

Figs. 1 (d-f) e 2

Pedicelo 12-30 mm; gineceu verde ou bege-esverdeado no material herborizado, estipe 4,5-7,5 $\mathrm{mm}$.

Material selecionado: BRASIL. RIO DE JANEIRO: Campos dos Goytacazes, 12.I.2005, M. C. Gaglianone MF39 (RB); São Francisco de Itabapoana, 21.X.2004, M. C. Gaglianone MC54 (RB).

Material adicional: BRASIL. ESPIRITO SANTO: Aracruz, Reserva da Santur-Coqueiral, 11.II.1993, R. N. Oliveira 170 (RB); Vitória, Campus da UFES, Floresta de tabuleiros, 18.IV.1985, O. J. Pereira 595 (RB).

É encontrada desde o Sergipe até o Rio de Janeiro, estendendo-se na porção leste de Minas Gerais. No Rio de Janeiro é encontrada principalmente em restingas.

Coletada com flores entre fevereiro e agosto e com frutos em outubro.

2. Swartzia glazioviana (Taub.) Glaz., Mém. Soc. bot. France 1(3): 155. 1906.

Figs. 1 (g-i) e 3

Árvore ca. $3 \mathrm{~m}$; ramos glabros a tomentosos. Folha com estípulas $1,5 \times 0,3 \mathrm{~mm}$, caducas, glabras; pecíolo 1,2-2 cm, acerosas, canaliculado, glabro a tomentoso; raque $7-11,4 \mathrm{~cm}$, marginada, glabra a tomentosa; peciólulo 1,1-1,7 mm, pubérulo a viloso-seríceo; folíolos 5-11, 2-4,1(-5) ×1-1,8 $(-2,5) \mathrm{cm}$, elípticos a ovados, cartáceos, pilosos na face abaxial, base cuneada a obtusa, ápice retuso, nervuras sulcadas a planas na face adaxial e muito proeminentes na face abaxial. Racemo ca. 7,3 cm, nas axilas ou em ramos áfilos, eixo velutino; brácteas ca. 1,3×0,8 mm, caducas, deltóides, velutinas; bractéolas 0,8-1,7 $\times 1 \mathrm{~mm}$, lanceoladas, inseridas acima da metade do pedicelo, velutinas; pedicelo ca. $1 \mathrm{~cm}$, achatado, tomentoso-velutino; botões ca. $8 \times 7 \mathrm{~mm}$, obladoglobosos, tomentoso-velutinos. Flor com cálice 4-5-lobado, lobos irregulares, internamente lanoso e externamente tomentoso-velutino; pétala branca, caduca juntamente com os estames, unha ca. 3,8 ×3,2 mm, lâmina ca. 1,8 $\times 2,2 \mathrm{~cm}$, oblada, serícea externamente; estames maiores 4 , filetes ca. $9,5 \mathrm{~mm}$, glabros, anteras ca. $4 \times 1,6 \mathrm{~mm}$, oblongas, glabras, estames menores com filetes ca. $6 \mathrm{~mm}$, glabros, anteras 1-1,5 $\times 1 \mathrm{~mm}$, oblongas, glabras, gineceu glabro, estipe $4,7 \mathrm{~mm}$, ovário ca. $5,8 \times 2,3 \mathrm{~mm}$, elíptico, 12 óvulos, estilete ca. $0,5 \mathrm{~mm}$, lateral, estigma punctiforme. Legume nucóide ca. $7 \times 2,3-3 \mathrm{~cm}$, elíptico a ovado, glabro a esparsamente estrigoso, 1-3 sementes, achatadas dorsiventralmente, esverdeadas e arilo ausente.

Material selecionado: BRASIL. RIO DE JANEIRO: Ararauma, 1981, D. Sucre 11311 (NY, RB); Arraial do Cabo, Praia Gorda, 20.IX.2003, H. G. Dantas 25 (RB); Búzios, 5.I.1995, M. Sanchez \& F. Pedroni 1000 (UEC); Cabo Frio, Campos Novos, 6.V.1987, H. C. Lima 2868 (NY); idem, Estrada de Armação de Búzios, 24.I.1952, H. Monteiro 3495 (R); idem, 14.IX.2002, A. Quinet $736(\mathrm{RB})$.

Esta espécie ocorre na restinga e é endêmica da Região dos Lagos no estado do Rio de Janeiro, uma área com alto grau de endemismo (Lacerda et al. 1993). A Região dos Lagos apresenta solos pouco desenvolvidos, normalmente rasos e condições climáticas secas com forte gradiente pluviométrico no trecho entre Rio de Janeiro e Cabo Frio (Ibraimo et al. 2004). A vegetação é composta principalmente por restingas situadas nas planícies sedimentares costeiras e devido às condições ambientais foi denominada por alguns autores como caatinga e mata seca (Nimer 1989).

Coletada com flores de novembro a janeiro e com frutos de janeiro a maio.

Gineceu glabro e cálice internamente lanoso são bons caracteres diagnósticos de $S$. glazioviana e ocorrem também em $S$. pickelii Killip ex Ducke (endêmica de Pernambuco) e 


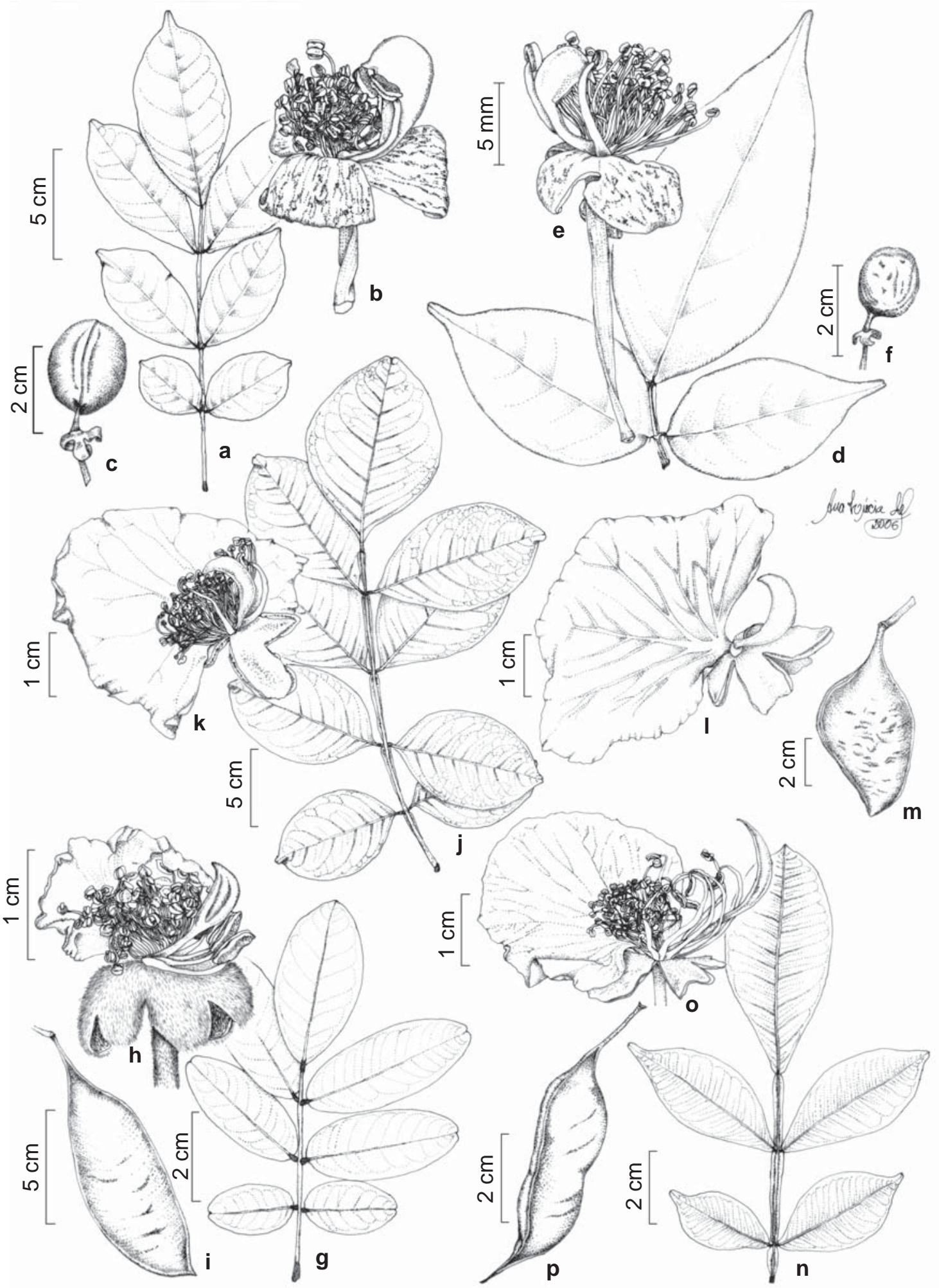

Figura 1 - a-c. Swartzia apetala var. apetala - a. folha; b. flor; c. fruto (a Ramos 152; b Araújo 9225; c Araújo 9290). df. S. apetala var. glabra - d. folha; e. flor; f. fruto (d, f Oliveira 170; e Pereira 595). g-i. S. glazioviana - g. folha; h. flor; i. fruto (g, i Ribeiro 125; h Ribeiro 243). j-m. S. langsdorffii - j. folha; k. flor completa; 1. flor após a queda dos estames; m. fruto (j, m Pessoal do Horto Florestal s.n. - RB 157081; k, 1 Lima 1758). n-p. S. myrtifolia var. elegans - n. folha; o. flor; p. fruto (n Schwacke 2915; o Pereira 04/134; p Martinelli 11751). 
S. bahiensis R.S.Cowan (endêmica da Bahia). S. glazioviana difere destas duas espécies no tamanho, forma e proporção dos folíolos e no comprimento da raque, além de apresentar distribuição geográfica distinta.

3. Swartzia langsdorffii Raddi, Mem. Mat. Fis. Soc. ital. Sci. Moderna 18: 396. 1820.

Figs. $1(j-m)$ e 3

Árvore 10-20 m, tronco marron-claro com fendas; ramos estrigosos a glabrescentes. Folha com estípulas 4-5×0,5 mm, subuladas, caducas, glabras; pecíolo $1,5-5 \mathrm{~cm}$, estrigoso a glabrescente, marginado a alado; raque 10$30 \mathrm{~cm}$, alada ou marginada, asa 4-5 mm larg., glabrescente; peciólulos 2-5 mm, estrigosos; folíolos 5-13, 4-10(-14) ×2-7 mm, elípticos a obovados, par basal menor, coriáceos, glabros a ligeiramente estrigosos na face abaxial, base aguda-cuneada a obtusa, ápice agudo-retuso, nervuras proeminentes em ambas as faces. Racemo $12-16 \mathrm{~cm}$, nas axilas e nos ramos áfilos, eixo estrigoso; brácteas ca. $2 \times 1 \mathrm{~mm}$, caducas, estrigosa; bractéolas 1-2 $\times 0,5 \mathrm{~mm}$, lanceoladas, persistentes, inseridas na metade do pedicelo, glabrescentes a estrigosas; pedicelos 15-20 × 7-9 mm, achatados glabrescentes a glabros; botões ca. $1 \mathrm{~cm}$ diâm., ovais, glabros. Flor com cálice 4-lobado, glabro internamente; pétala branca, persistente por mais tempo que os estames, glabra, unha 3-5 mm, lâmina 3-4×3-4(-5) cm, reniforme; estames maiores 4 , caducos, glabros, filetes $10-13 \mathrm{~mm}$, anteras ca. $3 \times 1,5 \mathrm{~mm}$, oblongas, estames menores glabros, filetes $7-12 \mathrm{~mm}$, anteras $0,5-1 \times 0,7-1,5 \mathrm{~mm}$, obladas; gineceu glabro, estipe 3-4 mm comp., ovário, ca. $7 \times$ 3-4 mm, encurvado-elíptico, estilete 1-1,5 mm, lateral, estigma punctiforme. Legume nucóide 6-10 × 4-8,5 cm, ovado-oblongo a obovado, achatado lateralmente, amarelo, suturas engrossadas, sementes bege e arilo amarelo. Material selecionado: BRASIL. RIO DE JANEIRO: Campos dos Goytacazes, 7.VI.2000, J. M. A. Braga 6005 (RB); Ilha de Marambaia, Restinga de marambaia, Praia da Gaeta, 12.VI.2000, L. F. T. Menezes 581 (RB); Imbé, Campos de Sossego do Imbé, Rio Sossêgo,
16.V.1989, G. Martinelli 13308 (RB); Mangaratiba, 4.I.1986, H. C. Lima 2645 (NY, RB); Magé, Piabetá, 29.XII.2001, A. Quinet 35/138 (RB); Miguel Pereira, São José, Sítio Xapuri, 14.V.2005, R. D. Ribeiro 464 (RB); Petrópolis, 23.II.1939, Vaccari s.n. (RB 78238); Rio Claro, Parque Ecológico da Prainha, 3.VII.2004, R. D. Ribeiro 311 (RB); Rio de Janeiro, 1.II.1968, L. B. Smith \& L. McWillians 15351 (NY); Santa Maria Madalena, Parque Estadual do Desengano, trilha da Rifa, 13.XI.1999, M. C. F. Santos 445 (RB); Silva Jardim, 30.V.1982, H. C. Lima 1758 (NY, RB).

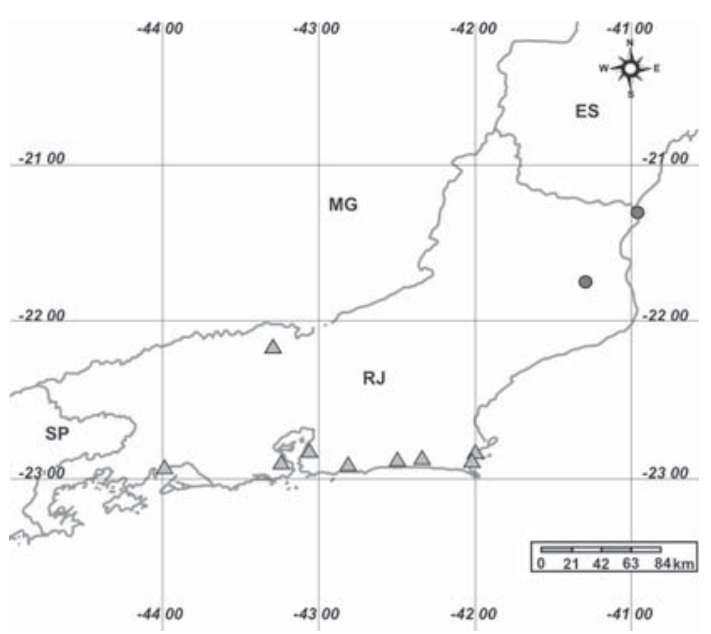

Figura 2 - Mapa de distribuição geográfica de Swartzia apetala var. apetala $\boldsymbol{\Delta}$ e $S$. apetala var. glabra $\bigcirc$ no estado do Rio de Janeiro.

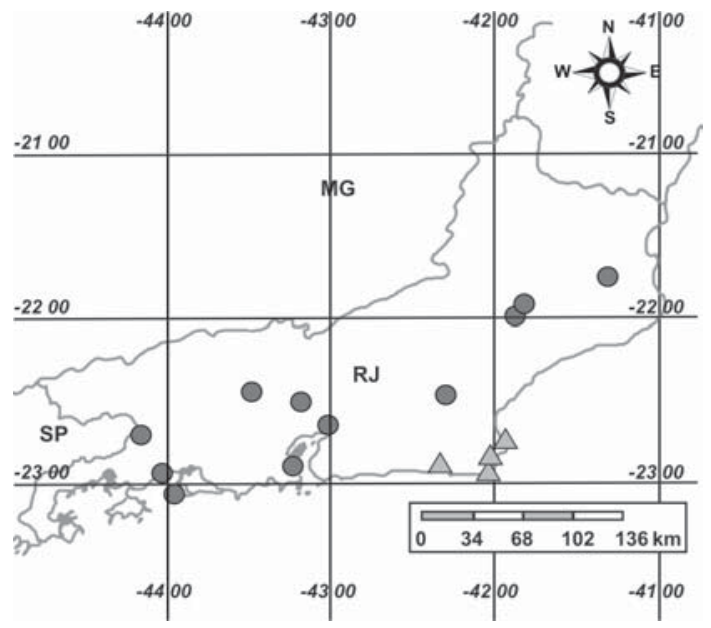

Figura 3 - Mapa de distribuição geográfica de Swartzia glazioviana $\mathbf{\Delta}$ e S. langsdorffii $\bigcirc$ no estado do Rio de Janeiro. 
Ocorre principalmente no Rio de Janeiro, estendendo-se ao norte até a Bahia e ao sul para São Paulo. É encontrada principalmente na mata atlântica em áreas de alta umidade durante todo o ano. Ocorre também na floresta estacional, onde é pouco abundante; não foi encontrada na restinga.

Coletada com flores de outubro a fevereiro e com frutos de abril a setembro.

4. Swartzia myrtifolia Sm., Rees'Cycl. 34. 1816.

Representada na Região Sudeste apenas por S. myrtifolia var. elegans.

4.1 Swartzia myrtifolia var. elegans (Schott) R.S. Cowan, Fl. Neotrop. Monogr. 1: 168. 1968.

Figs. 1 (n-p) e 4

Árvore 3-12 m; tronco cinza claro com cicatrizes; ramos glabros a estrigosos. Folha com estípulas, $2-3,8 \times 0,1-0,8 \mathrm{~mm}$, persistentes, subuladas, glabras a estrigosas externamente; pecíolo $0,6-1,5 \mathrm{~cm}$, alado a marginado, asa $1-$ $4,1 \mathrm{~mm}$ larg.; raque $2,3-8,5 \mathrm{~cm}$, alada, asa 0,8-4,5 mm larg., glabra a pubérula; peciólulo 0,9-2,4 mm, estrigoso a glabro; folíolos 5-15, $1,2-5,7 \times 0,7-3,5 \mathrm{~cm}$, ovais a obovados, o par basal menor que os demais, cartáceos, face adaxial glabra e abaxial glabra a estrigosa, base aguda a cuneada, ápice agudo a retuso mucronado, nervuras proeminentes em ambas as faces. Racemo 5,9-7 cm, terminal, eixo estrigoso, ca. 3-5 flores; brácteas 1-1,5×0,4$0,8 \mathrm{~mm}$, persistentes, linear-lanceoladas, estrigulosa; bractéolas ca. 1,5 ×0,2-0,5 mm, na base do pedicelo, linear-lanceoladas, estrigulosa; pedicelo $1-2,5 \mathrm{~cm}$, glabro a denso-estrigoso; botões 4,4-9,3 ×3,5-8,6 mm, ovais a globosos, glabros a estrigosos. Flor com cálice 4-lobado, lobos elípticos, glabros internamente; pétala amarela, glabra, caduca juntamente com os estames, unha 2,2-4,8 $\times 1-$ 1,9 mm, lâmina $1-2,5 \times 1,2-3 \mathrm{~cm}$, oblada e cordada; estames maiores $4-8$, filetes $1,6-2 \mathrm{~cm}$, glabros, amarelos, anteras $1,8-3,1 \times 0,9-1,5 \mathrm{~mm}$, oblongas, creme, estames menores glabros, filetes 9-12 mm, amarelos, anteras 1-1,4 $\times$ 0,8-1,2 mm, obovadas ou largo-oblongas; gineceu glabro, estipe 10-12,5 mm, ovário 5,5$8 \times 1-1,5 \mathrm{~mm}, 14$ óvulos, estilete $2,5-4,2 \mathrm{~mm}$, reto, terminal, estigma capitado. Legume 3,4-6,2×1,2-1,8 cm, 1-2 sementes, elíptico ou moniliforme, glabro, alaranjado, sementes pretas e arilo branco.

Material selecionado: BRASIL. RIO DE JANEIRO: Magé, Piabetá, 4.III.2001, A. Quinet 28/76 (RB); Mangaratiba, Reserva Ecológica de Rio das Pedras, s.d., A. Costa 470 (RB); Maricá, Barra de Maricá, 21.IX.1980, K. Yamamoto s.n. (UEC 25181); Nova Friburgo, 12.VIII.2005, R. D. Ribeiro 524 (RB); idem, Muri, Macaé de Cima, floresta pluvial costeira, nascente do Rio das Flores, 1000 ms.m, G. Martinelli 11751 (RB); Nova Iguaçu, Leito do Rio Serra Velha, 11.IV.1996, P. R. Farag 231 (RB); Parati, 3.VII.1989, H. C. Lima 3627 (RB); Petrópolis, Cachoeira do Capoeirão, 26.IX.1977, G. Martinelli \& C. G. Costa 3045 (NY); Resende, 21.VI.1927, J. G. Kuhlmann 46 (RB); Rio Claro, Distrito de Lídice, 15.XII.2001, F. B. Pereira 04/ 134 (RB); Rio de Janeiro, s.d., A. F. M. Glaziou 9414 (NY); Santa Maria Madalena, 20.X.1990, A. F. Vaz 826 (RB); Teresópolis, 20.V.1943, W. D. Barros 1226 (NY, RB).

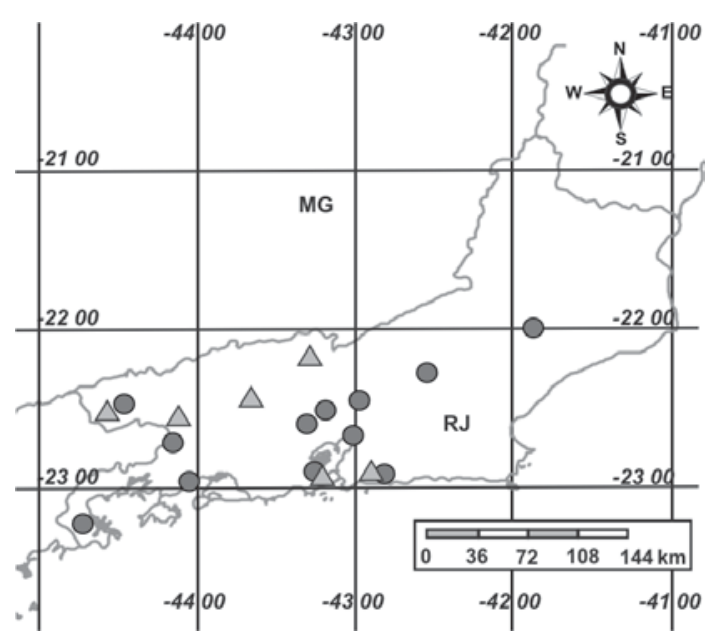

Figura 4 - Mapa de distribuição geográfica de Swartzia myrtifolia var. elegans $\boldsymbol{\Delta}$ e S. submarginata var. submarginata no estado do Rio de Janeiro. 
Foi encontrada no sul da Bahia, leste de Minas Gerais e próximo à faixa litorânea do Espírito Santo e do Rio de Janeiro.

Coletada com flores praticamente o ano inteiro com pico de floração entre os meses de novembro a janeiro.

S. myrtifolia var. elegans é muito próxima de $S$. simplex, diferindo por apresentar pétalas menores e mais frágeis, folhas com 5 ou mais folíolos, ovário mais estreito e tronco mais claro com marcas de cicatrizes.

5. Swartzia oblata R.S. Cowan, Brittonia 33(1): 11. 1981.

Figs. 5 (a-c) e 6

Árvore 10-12 m; tronco vermelho, descamante, ramos glabros a pubérulos. Folha com estípulas 6-10 × 1-1,6 mm, subuladas, caducas, tomentosas; pecíolo 1,5-4 cm, glabro a tomentoso; raque $15-30 \mathrm{~cm}$, marginada, glabra a tomentosa; peciólulos $1,5-3 \mathrm{~mm}$, glabros a tomentosos; folíolos 11-21, $(-2,8)$ $5,5-9 \times 1,7-3,5 \mathrm{~cm}$, elípticos a ovais, cartáceos a coriáceos, glabrescentes a pubérulos na face abaxial, base aguda e ápice acuminado-mucronado, nervuras pouco proeminentes na face adaxial e muito proeminentes na face abaxial. Racemo ou panícula $6-30 \mathrm{~cm}$, nas axilas ou em ramos áfilos, eixo pubérulo a tomentoso; brácteas $2-2,5 \times 1-2 \mathrm{~mm}$, deltóides, caducas, estrigosas a tomentosas; bractéolas 1,3-2,5 $\times 1 \mathrm{~mm}$, subuladas, inseridas acima da metade do pedicelo, estrigosas a tomentosas; pedicelo 4,5-12 mm, estrigosos a tomentosos; botões globosos, 6-9 mm diâm., pubérulos a tomentosos. Flor com cálice 4-lobado, lobos irregulares, glabros internamente, eretos; pétala branca, caduca juntamente com os estames, unha 4-6,5 × 3-6 mm, lâmina 13$15 \times 13-17 \mathrm{~mm}$, oblada, base cordada, levemente serícea externamente; estames amarelos, maiores 4 , filetes $8-12 \mathrm{~mm}$, velutino a piloso, anteras $2,5-3 \times 1,2-1,6 \mathrm{~mm}$, oblongas, glabras, estames menores, filetes glabros, anteras $0,7-1 \times 0,7-1 \mathrm{~mm}$, elípticas, obladas ou oblongas, glabras; gineceu com estipe 5,3-7,7 mm, serícea, ovário 5,9-7,5× 2,3-3 mm, arco-elíptico, 16 óvulos, seríceo, estilete 1,3-2 mm, lateral, encurvado, glabro, estigma punctiforme, glabro. Legume nucóide 5,9-13,5 × 2,8-4 cm, (-1)3-7 sementes, retos, elípticos, circulares ou oblongos, verdes, esparso-estrigoso a tomentoso, sementes beges e arilo amarelo.

Material selecionado: BRASIL. RIO DE JANEIRO: Araruama, 27.III.2004, R. D. Ribeiro 153 (RB); Guapimirim, 19.III.2001, F. B. Pereira 26/80 (RB); Itaguaí, 14.VI.1992, A. L. Peixoto s.n. (RB 322353); Itatiaia, Parque Nacional do Itatiaia, 11.IV.1946, N. Lima 16 (RB); Macaé, 21.XI.2002, M. G. Bovini 2254 (RB); Magé, 3.VI.1985, S. M. Faria 247 (RB); Niterói, 25.IX.1991, P. C. Fevereiro s.n. (RB 345066); Nova Friburgo, 19.III.2001, A. Quinet 35/81 (RB); Nova Iguaçu, 29.III.2000, A. T. Ramalho 25 (RB); Parati, 8.III.1994, R. Marquete 1507 (RB); Petrópolis, 1948, O. C. Góes 108 (RB); Rio Bonito, Reserva Botânica das Águas Claras, 23.III.1992, R. Spruce 11418 (RB); Rio de Janeiro, VII.2002, J. E. Meireles s.n. (RB 362170); Santa Maria Madalena, Parque Estadual do Desengano, 27.VI.1987, $H$. C. Lima 3024 (RB); Sapucaia, 31.XII.2000, F. M. B. Pereira 38/60 (RB); Saquarema, 23.II.2006, $R$. D. Ribeiro 614 (RB); Silva Jardim, Reserva Biológica de Poço das Antas, 26.V.1982, G. Martinelli 8465 (RB); Valença, 25.VIII.2000, M. L. C. V. Spolidoro 272 (RB).

Ocorre no sul da Bahia, Espírito Santo, leste de Minas Gerais e na faixa litorânea dos estados do Rio de Janeiro e São Paulo.

Coletada com flores de fevereiro a julho e com frutos de setembro a novembro.

Swartzia oblata foi descrita por Cowan (1981) e foi caracterizada pela pétala oblada, folíolos glabros e agudos, androceu decíduo e botões costados. Cowan (1981) considerou esta espécie próxima de $S$. flaemingii Raddi e $S$. macrostachya Benth. e não mencionou qualquer semelhança entre S. oblata R.S. Cowan e S. acutifolia var. ynesiana R.S. Cowan. Mansano \& Tozzi (2001) sinonimizaram estes dois táxons. 


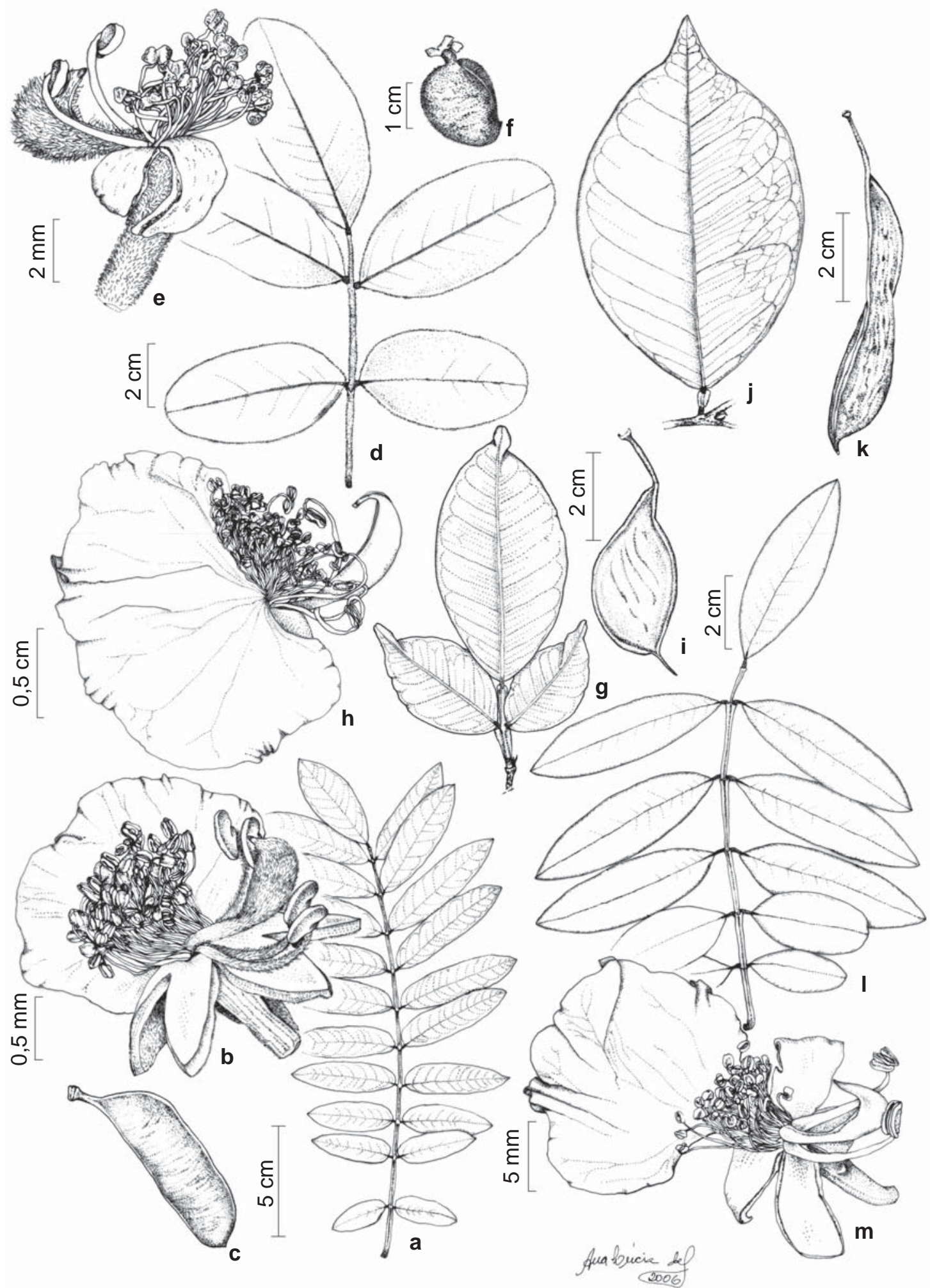

Figura 5 - a-c. Swartzia oblata - a. folha; b. flor; c. fruto (a Bovini 2254; b Ribeiro 582; c Lima 375). d-f. S. pilulifera - d. folha; e. flor; f. fruto (d, f Lima 291; e Lima 209). g-i. S. simplex var. grandiflora - g. folha; h. flor; i. fruto (g, i Giordano 1017; h. Sucre 7384). j-k. S. simplex var. continentalis - j. folha; k. fruto (j-k Kuhlmann s.n. RB 756). 1-m. S. submarginata var. submarginata - 1. folha; m. flor (1-m Barros 288). 
6. Swartzia pilulifera Benth., J. Bot. (Hooker) 2: 90. 1840. Figs. 5 (d-f) e 6

Árvore 2-8 m; ramos estrigosos a tomentosos. Folha com estípulas $(1,7-)$ $2,6-4,5(-5,5) \times 0,5-1,15 \mathrm{~mm}$, subuladas, persistentes, esverdeadas, tomentosas a seríceas; pecíolo $(0,8-) 1-2,3 \mathrm{~cm}$, tomentoso a seríceo; raque $2,5-9 \mathrm{~cm}$, alada ou marginada, asa, 0,1-0,4 cm larg., estipelada, esparsamente tomentosa a velutina; obtriangular a marginada; peciólulo 1-2,9 $\mathrm{mm}$, pubérulo a viloso; folíolos 5-9, 2,4-5,7(-9) × 1,1$3,2 \mathrm{~cm}$, elípticos a obovados, cartáceos, glabros a velutinos na face adaxial, velutinos na face abaxial, base cuneada a inequilateral, ápice retuso, nervuras sulcadas a planas na face adaxial, muito proeminentes na face abaxial. Racemo ou panícula 4,8-15,5 $\mathrm{cm}$, nas axilas e nos ramos áfilos, eixo pubérulo a velutino; brácteas $1,6-5,4 \times 0,4 \mathrm{~mm}$, linearlanceolada, pubérulas a velutinas; bractéolas ausentes; pedicelo $3,2-6,2(-8,1) \mathrm{mm}$, pubérulo a velutino; botões 3,6-5,5 ×2,94,1 mm, globosos apiculados, pubérulos a velutinos. Flor com cálice 3-4-lobado, lobos irregulares, glabro internamente; pétala ausente; estames amarelos, maiores 2 , filetes 1,9-3,6 mm, glabros, anteras 1-1,5 $\times 0,6-0,7 \mathrm{~mm}$, oblongas, glabras, estames menores com filetes $3,6-4,4 \mathrm{~mm}$, glabros, anteras $0,5-0,7 \times 0,6-0,7 \mathrm{~mm}$, obladas, glabras; gineceu com estipe 2,9-3,5 mm, lanosa, ovário 2,9-4,4 × 1,7-2,5 mm, largo-elíptico, lanoso, 7-6 ovulado, estilete 0,5-0,8 mm., lateral, glabro, estigma punctiforme. Legume 2-2,6 $\times 0,9-1,7 \mathrm{~cm}$, oval, piloso, 1-seminado, sementes pretas, arilo branco.

Material selecionado: BRASIL. RIO DE JANEIRO: Cabo Frio, Tamoios, 22.II.2006, R. D. Ribeiro 594 (RB); Itatiaia, Parque Nacional do Itatiaia, Lago Azul, 17.XII.1940, W. D. Barros 136 (RB); Rio Bonito, 28.VII.1989, N.T. Silva s.n. (RB 330960); São José do Vale do Rio Preto, 11.I.2001, F. B. Pereira 04/63 (RB).

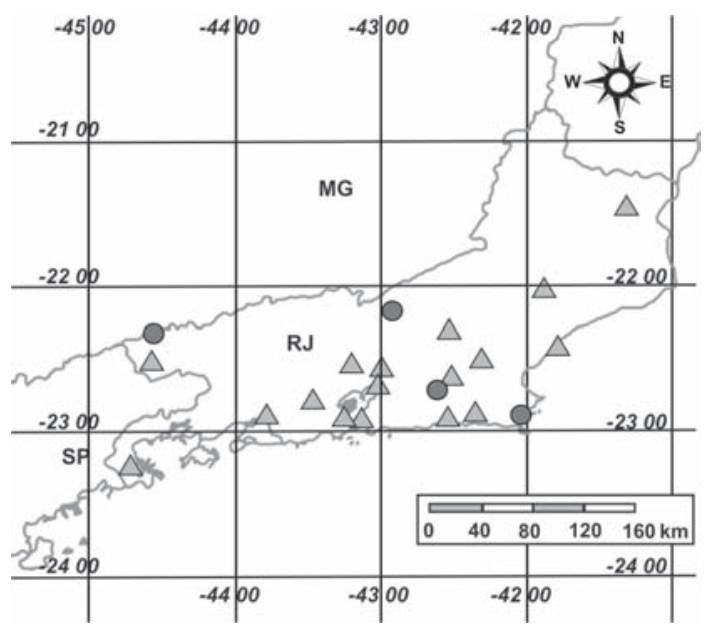

Figura 6 - Mapa de distribuição geográfica de Swartzia oblata $\boldsymbol{\Delta}$ e S. pilulifera $\bigcirc$ no estado do Rio de Janeiro.

Em Minas Gerais ocorre na Cadeia do Espinhaço e no Vale do Rio Doce. No estado do Rio de Janeiro ocorre principalmente na Serra da Mantiqueira, aparecendo também no município de Cabo Frio, na região dos Lagos.

Coletada com flores de julho a fevereiro e com frutos em abril.

7. Swartzia simplex (Sw.) Spreng., Syst. veg. 4(2): 567.1825.

Árvore ou arvoreta 4-18 m, tronco preto ou cinza liso com lenticelas; ramos glabros. Folha com estípulas 3-6×0,5-1 mm, subuladas, pubérulas a glabras (raro); pecíolo $0,5-1,5 \times$ $0,3 \mathrm{~cm}$, glabro; raque $7,5-12,7 \mathrm{~cm}$, alada, asa $0,1-0,5 \mathrm{~cm}$; peciólulo maior que $1 \mathrm{~mm}$; folíolos 1-3, 4-11 ×2,5-5,5 cm, elípticos a ovados, o terminal, quando presente, maior, cartáceos, glabros, base atenuada a obtusa, ápice acuminado, nervura central fortemente proeminente na face abaxial. Racemos 4,5-5,5 cm, nas axilas, eixo glabro; brácteas ca. $1 \times 0,5 \mathrm{~mm}$, tomentosa a pubérula; bractéolas $1-1,5 \times 0,5-0,7 \mathrm{~cm}$, deltóides, inseridas na base do pedicelo, tomentosas a pubérulas; pedicelos $1,5-3 \mathrm{~cm}$; botões $0,7-1,3 \times 0,6-1 \mathrm{~cm}$, circulares a obtusos, 


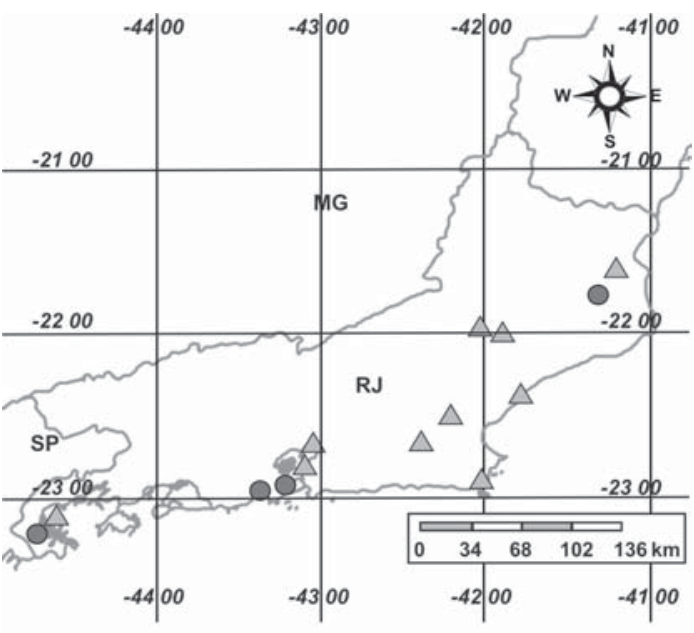

Figura 7 - Mapa de distribuição geográfica de Swartzia simplex var. grandiflora $\mathbf{\Delta}$ e S. simplex var. continentalis

glabros. Flor com cálice 4-5-lobado, glabro em ambas as faces; pétala amarela, glabra, caduca juntamente com os estames, unha 3-4 $\times 2 \mathrm{~mm}$, lâmina 2,5 ×3-4 cm, reniforme, base cordada; estames maiores 6-11, glabros, filetes $1,5 \mathrm{~cm}$, anteras ca. $4 \times 2 \mathrm{~mm}$, oblongas, estames menores glabros, filetes $0,7-1 \mathrm{~cm}$, anteras ca. $2 \times 1 \mathrm{~mm}$, elípticas; gineceu glabro, estipe 7$12 \mathrm{~mm}$, ovário, 7-13 × 2-3 mm, encurvadoelíptico, estilete $3-5 \mathrm{~mm}$, terminal, estigma capitado. Legume 3,5-7,5 ×1,2-2 cm, oblongoelíptico a oboval, amarelo, deiscente, sementes pretas, arilo branco, adocicado.

No estado do Rio de Janeiro é representada por duas variedades descritas a seguir.

\subsection{Swartzia simplex var. grandiflora} (Raddi) R.S. Cowan, Fl. Neotrop. Monogr. 1: 172. 1968.

Figs. 5 (g-i) e 7

Árvore 10-18 m; tronco 15-20 cm diâm., cinza, liso com lenticelas. Folhas trifolioladas. Material selecionado: BRASIL. RIO DE JANEIRO: Cabo Frio, Praia do Peró, 14.IX.2002, A. Quinet 727 (RB); Campos dos Goytacazes, Bom Jesus, 17.V.2000, J. M. A. Braga 5927 (RB); Casimiro de Abreu, 13.VIII.1986, G. Martinelli 11640 (RB); Macaé, Mata de Restinga do Forte Mal. Hermes, 15.V.1993, J. R. Pirani \& R. Mello Silva 2865 (NY, SPF); Magé, 7.IV.1984, R. Guedes 732 (RB); Parati,
Ilha dos Côcos, 15.IV.1991, L. C. Giordano 1104 (RB); idem, 10.III.1987, N. M. L. Cunha \& J. Nakajima 2 (HRCB); Rio de Janeiro, I.1917, F. C. Hoehne 146 (SP); idem, Parque Ecológico da Prainha, 3.VII.2004, R. D. Ribeiro 312 (RB); idem, Jacarepaguá, s.d., E. Pereira 739 (NY); Santa Maria Madalena, Santo Antônio do Imbé, IV.1932, A. C. Brade 11722 (R); Silva Jardim, Reserva Biologica de Poço das Antas, 16.VIII.1995, J. M. A. Braga 2667 (R, RB).

Amplamente distribuída do sudeste do México até a América Central, norte da Colômbia, oeste do Peru e Bolívia. No Brasil, ocorre principalmente no estado do Rio de Janeiro, estendendo-se ao norte até o Pará e ao sul até o Rio Grande do Sul. No estado do Rio de Janeiro foi encontrada principalmente em solos arenosos.

Coletada com flores de agosto a janeiro e com frutos de maio a agosto.

7.2 Swartzia simplex var. continentalis Urb., Symb. Antill. 5(3): 364-365. 1908.

Figs. 5 (j, k) e 7

Arvoreta 4-8 m, tronco 5-10 cm diâm., preto. Folhas unifolioladas.

Material selecionado: BRASIL. RIO DE JANEIRO: Campos dos Goytacazes, Rio Doce, 15.IX.1943, J. G. Kuhlmann 6451 (NY); Parati, 28.IV.1993, $R$. Marquete 889 (RB); Rio de Janeiro, Represa do Camorim, Jacarepaguá, s.d., J. G. Kuhlmann s.n. (RB 756, US 2369046).

Este táxon foi tratado no nível varietal pela primeira vez por Cowan (1968) como Swartzia simplex var. ochnacea (DC.) R.S. Cowan, porém Torke (comunicação pessoal) verificou que $S$. simplex var. continentalis, que foi publicado em 1908, é um sinônimo que tem prioridade no nível varietal, sendo então o nome adotado para o táxon neste tratamento.

Ocorre com maior abundância na região amazônica. Apresenta uma ampla distribuição desde a Guatemala até a Colômbia no oeste da América do Sul e até o estado do Rio de Janeiro na costa leste. Na Região Sudeste notase claramente o estado do Rio de Janeiro como limite sul de distribuição. 
Coletada com flores entre outubro e novembro e com frutos entre junho e julho.

\section{Swartzia submarginata (Benth.) Mansano,} Kew Bull. 56: 924. 2001.

No Rio de Janeiro é representada apenas pela variedade típica.

\subsection{Swartzia submarginata (Benth.) Mansano var. submarginata.}

Figs. $5(1, \mathrm{~m})$ e 4

Árvore 10-12 m. Folha com estípulas 1,5-3 $\times 0,5-0,7 \mathrm{~mm}$, pubescentes; pecíolo 1,5$2,5 \mathrm{~cm}$, estrigoso a glabrescente; raque 7,5$20 \mathrm{~cm}$, pubérula; peciólulo $1-2,3 \mathrm{~mm}$, pubérulo; folíolos 11-21, 4-7,7×1,4-2,5 cm, ovados a elípticos, os basais menores, membrano-cartáceos, face adaxial glabra a estrigosa e abaxial estrigosa, nervuras proeminentes na face abaxial. Panícula 23$45 \mathrm{~cm}$, nas axilas ou em ramos áfilos, eixo pubérulo a velutino; brácteas $0,8-1,5 \times 0,7 \mathrm{~mm}$, deltóides, seríceas; bractéolas ca. 0,5-1×0,5 mm, deltóides, inseridas acima da metade do pedicelo, serícea; pedicelo $10-22 \mathrm{~mm}$, pubérulo a velutino; botões 5,5-7 × 4,8-5,5 mm, globosos a ovados, ápice agudo, pubérulos a tomentosos. Flor com cálice 3-5-lobado, lobos irregulares, flexuosos, glabros internamente; pétala branca, caduca juntamente com os estames, serícea a velutina externamente, unha 3,5-4,5 × 2,6 mm, lâmina 9,3-13 × 10,5$14 \mathrm{~mm}$, oblada; estames amarelos, maiores 2-4, filetes 4,7-7 $\mathrm{mm}$, esparso-vilosos a velutinos, anteras oblongas $3,5-4 \times 1,3-1,7 \mathrm{~mm}$, glabras, estames menores glabros, filetes ca. 4,5-6 mm, glabros, anteras ca. $1 \times 1 \mathrm{~mm}$, elípticas a obladas; gineceu glabro, estipe 3,55 mm comp., ovário $3-4 \times 1-1,5 \mathrm{~mm}$, elíptico a obovado, 6-16 óvulos, estilete $0,6-1,2 \mathrm{~mm}$, lateral, reto, estigma punctiforme. Fruto legume nucóide, ca. $7 \times 4 \mathrm{~cm}$, arqueado-elíptico, glabro, esverdeado, ca. 8 sementes beges e arilo amarelo.

Material selecionado: BRASIL. RIO DE JANEIRO: Itatiaia, Macieiras, 16.V.1941, W. D. Barros 288 (RB); Nova Iguaçu, Reserva Biológica de Tinguá,
24.I.2006, R. D. Ribeiro 566 (RB); Paraíba do Sul, 3.I.1938, E. Kuhlmann s.n. (UEC 84692); Resende, Horto Florestal, 5.V.1928, s.c., s.n. (RB 157083); Vassouras, 20.II.1978, M. Santos 05 (RB); Volta Redonda, 18.III.2003, H. C. Lima 6085 (RB).

Ocorre principalmente na Serra da Mantiqueira nos estados de Minas Gerais, Rio de Janeiro e São Paulo, onde também é encontrada próximo ao litoral.

Coletada com flores de fevereiro a junho e com frutos de outubro a janeiro.

\section{Agradecimentos}

Aos curadores dos herbários citados pelo empréstimo de material ou pela facilitação de acesso ao acervo; à Petrobras pelo auxílio financeiro (convênio Petrobras/JBRJ: 610.4.025.02.3); à Ana Lúcia de Souza pela confecção das ilustrações; aos revisores anônimos pelas boas sugestões ao manuscrito.

\section{REFERÊNCIAS BIBLIOGRÁFICAS}

Barneby, R. C. 1991. Notes on Swartzia (Leguminosae: Swartzieae) preliminary to the flora of the Venezuelan Guayana. Annals of the Missouri Botanical Garden 78(1): 177-183. 1992. Centennial beans: a miscellany of American Fabales. Brittonia 44(2): 224-239.

Costa, D. P.; Imbassahy, C. A. A. \& Silva, V. P. A. V. 2005. Diversidade e importância das espécies de briófitas na conservação dos ecossistemas do estado do Rio de Janeiro. Rodriguésia 56(87): 13-49.

Cowan, R. S. 1968. Swartzia (LeguminosaeCaesalpinioideae, Swartzieae). Flora Neotropica Monograph 1. Hafner, New York, 228p.

1981. New taxa of LeguminosaeCaesalpinioideae from Bahia, Brazil. Brittonia 33(1): 9-14. 1985. Studies in tropical American Leguminosae. Brittonia 37(3): 291-304.

Doyle, J. J.; Doyle, J. L.; Ballenger, J. A.; Dickson, E. D.; Kajita, T. \& Ohashi, H. 
1997. A phylogeny of the chloroplast gene $r b c \mathrm{~L}$ in the Leguminosae: Taxonomic correlations and insights into the evolution of nodulation. American Journal of Botany 84(4): 541-554.

Herendeen, P. 1995. Phylogenetic relationships of the tribe Swartzieae. In: Crisp, M. D. \& Doyle, J. J. (eds.). Advances in legume systematics, part 7, phylogeny. Royal Botanic Gardens, Kew. Pp. 123-132.

Holmgren, P. K. \& Holmgren, N. H. (eds.). 1998 onwards (continuously updated). Index Herbariorum. New York Botanical Garden. http://sciweb.nybg.org/science2/ IndexHerbariorum.asp

Ibraimo, M. M.; Schaefer, C. E. G. R.; Ker, J. R.; Lani, J. L.; Rolim-Neto, F. C.; Albuquerque, M. A. \& Miranda, V. J. 2004. Gênese e micromorfologia de solos sob vegetação xeromórfica (caatinga) na Região dos Lagos (RJ). Revista Brasileira de Ciências do Solo 28: 695-712.

Lacerda, L. D.; Araujo, D. D \& Maciel, N. 1993. Dry coastal ecosystems of the tropical Brazilian coast. In: Maarel, E. van der. (ed.). Ecosystems of the world 2B: Dry coastal ecosystems Africa, America, Asia and Oceania. Elsevier, Amsterdam. Pp. 477-493.

Mansano, V. F. 1997. Estudos taxonômicos da tribo Swartzieae (DC.) Benth. (Leguminosae - Papilionoideae) no Sudeste do Brasil. Dissertação de Mestrado. Universidade Estadual de Campinas, Campinas, 140p.

Mansano, V. F. \& Souza, A. L. 2005. A new Swartzia (Leguminosae: Papilionoideae: Swartzieae) species with trimorphic stamens from Amazonian Brazil. Botanical Journal of the Linnean Society 147: 235-238.

Mansano, V. F. \& Tozzi, A. M. G. A. 1999. The taxonomy of some Swartzieae (Leguminosae, subfam. Papilionoideae) from southeastern Brazil. Brittonia 51(2): 149-158.
2001. Swartzia Schreb. (Leguminosae: Papilionoideae: Swartzieae): a taxonomic study of the Swartzia acutifolia complex including a new name and a new species from southeastern Brazil. Kew Bulletin 56(4): 917-929.

Mori, S. A. 1989. Eastern, extra-Amazonian Brazil. In: Campbell, D. G. \& Hammond, H. D. (eds.) Floristic inventory of tropical countries: the status of plant systematics, collections, and vegetation, plus recommendations for the future. The New York Botanical Garden, New York. Pp. 427-454.

Nimer, E. 1989. Climatologia do Brasil. Rio de Janeiro. Instituto Brasileiro Geografia e Estatística, Rio de Janeiro, 421p.

Peixoto, A. L. 1991/92. Vegetação da costa atlântica. In: Monteiro, S. \& Kaz, L. (coords.) Floresta Atlântica. Edições Alumbramento, Livroarte Editora, Rio de Janeiro. Pp. 33-42.

Pennington, R. T.; Lavin, M.; Ireland, H.; Klitgaard, B.; Preston, J. \& Hu, J. 2001. Phylogenetic relationships of basal papilionoid legumes based upon sequences of chloroplast $\operatorname{trn} \mathrm{L}$ intron. Systematic Botany 26: 537-556.

Pipoly, J. J. \& Rudas, A. 1994. New species of Swartzia (Fabaceae: Faboideae) from Amazonia. Novon 4: 165-168.

Polhill, R. M. 1981. Papilioniodeae. In: Polhill, R. M. \& Raven, P. H. (eds.). Advances in legume systematics, part 1. Royal Botanic Gardens, Kew. Pp. 191-208.

Torke, B. M. 2004. Two new species of Swartzia (Leguminosae) from the Amazon basin of Brazil, with notes on the genus and a key to the unifoliolate species. Systematic Botany 29: 358-365.

2007. New combinations and specieslevel synonyms in Swartzia (Fabaceae: Papilionoideae). Novon 17: 110-119. 


\section{Lista de Exsicatas}

Alemão, F.: RB 5200 (3)

Almeida, C.: 220 (7.1), RB 1871 (7.1), RB 82205 (3), RB 418303 (7.1)

Angeli, C.: 333 (7.1)

Araújo, D.: 3376 (7.1), 6346 (1.1), 8622 (1.1), 8793 (7.1), 9225 (1.1), $9290(1.1)$

Barbara, T.: 06 (7.1)

Barros, W.D.: 136 (6), 220 (5), 269 (6), 288 (8.1), 289 (6), 1226 (4.1)

Boher, C.B.A.: RB 360150 (5)

Bovini, M.G.: 467 (7.1), 2254 (5), 2452 (4.1)

Brade, A.C.: 11722 (7.1)

Braga, J.M.A.: 2667 (7.1), 5927 (7.1), 6005 (3)

Campos, M.D.: 42 (7.1), 111 (3)

Carauta, J.P.P.: 1842 (7.1)

Costa, A.: 470 (4.1)

Costa, E.L.: 202 (7.1)

Costantino, D.: RB 7608 (3)

Cunha, N.M.L.: 2 (7.1)

Damasceno, R.N.: 560 (1.1)

Dantas, H.G.: 25 (2)

Duarte, A.P.: 63 (5), 5499 (5), 5741 (4.1), 8749 (1.1)

Ducke, A.: RB 23337 (4.1)

Eisler, E.: RB 11163 (1.1)

Farág, P.R.: 137 (5), 166 (4.1), 191 (5), 194 (5), 212 (5), 231 (4.1), 315 (2), 573 (1.1)

Faria, S. .: 247 (5), 604 (5), 923 (2), 933 (1.1), 1219 (2), RB 364912 (7.1)

Farney, C.: 1128 (1.1), 2399 (5), 3178 (1.1), 3674 (1.1), 3749 (1.1)

Fernandes, D.: 114 (2), 196 (1.1), 211 (1.1), 243 (1.1), 292 (2), 380 (1.1)

Fevereiro, P.C.: RB 345066 (5)

Fonseca, V.S.: 207 (1.1)

Fontella, J.: 2898 (1.1), 3055 (1.1), 3070 (1.1), $3105(1.1)$

Fraga, C.N.: 1130 (7.1)

Frazão, A.: RB 7701 (7.1)

Frutuoso, L.C.F.: 83 (7.1)

Gaglianone, M.C.: MF39 (1.2), MC54 (1.2)

Giordano, L.C.: 790 (7.1), 890 (7.1), 1017 (7.1),
1104 (7.1), 1340 (7.1), 1661 (7.1), 1729 (7.1), $1760(7.1)$

Glaziou, A.F.M.: 914 (4.1), RB 17043 (4.1)

Góes, O.C.: 108 (5), 953 (4.1), 1204 (4.1)

Gomes, M.: 555 (1.1)

Guedes, B.H.: 593 (7.1)

Guedes-Bruni, R.: 8 (7.1), 263 (7.1), 732 (7.1), RB 252727 (7.1)

Hoehne, F.C.: 146 (7.1)

I.R.C.: RB 283170 (4.1), RB 283166 (3), RB $283172(7.1)$

Kanno, T.: 413 (7.1)

Klein, V.L.G.: 987 (7.1)

Kuhlmann, E.: UEC 84692 (8.1)

Kuhlmann, J.G.: 46 (4.1), 641 (7.2), NY 1441932 (1.1), RB 741 (7.1), RB 756 (7.2), RB 11815 (1.1), RB 15335 (1.1), RB 15336 (1.1), RB 102334 (1.1), RB 418299 (1.1), US 2369046 (7.2)

Kurtz, B. C.: RB 328347 (4.1)

Lage, C.A.: NY 2369063)

Leitman, M.: 208 (4.1)

Lewis, G.P.: 1189 (1.1), 1614 (1.1)

Lima, H.C.: 110 (7.1), 561 (1.1), 1101 (7.1), 1758 (3), 1782 (7.1), 2645 (3), 2802 (1.1), 2867 (2), 2868 (2), 2985 (3), 3024 (5), 3575 (2), 3627 (4.1), 3647 (5), 5239 (4.1), 5249 (8.1), 5748 (5), 5949 (5), 6085 (8.1), 6185 (1.1), 6235 (5), 6350 (1.1)

Lima, J. S.: RB 34427 (4.1)

Lima, N.: 16 (5)

Lobão, A. Q.: 361 (2), 369 (2), 382 (2), 422 (1.1)

Machado, O.: RB 75461 (5), RB 75706 (5)

Marques, M.C.M.: 147 (7.1), 404 (7.1), 422 (5)

Marquete, N.: 275 (7.1)

Marquete, R.: 173 (4.1), 889 (7.2), 1133 (7.1), 1249 (7.1), 1345 (7.1), 1496 (7.1), 1507 (5), 1826 (7.1), $3519(1.1)$

Martinelli, G.: 1758 (4.1), 3045 (4.1), 8465 (5), 11640 (7.1), 11751 (4.1), 13308 (3)

Meireles, J. E.: RB 362170 (5), RB 368827 (3), RB 410336 (3)

Mello, C.: 06 (7.1), 11 (7.1), RB 66503 (5)

Menezes, L.F.T.: 581 (3) 
Moura, L. C.: 26 (7.1)

Nadruz, M.: 22 (4.1), 443 (4.1), RB 253499 (4.1)

Nunes, G.M.: 197 (3)

Occhioni, P.: RB 2181 (5)

Oliveira, R.N.: 170 (1.2)

Otávio, D.: 79 (4.1)

Paes, L.E.: RB 64914 (4.1)

Peckolt, G.: RB 15334 (3)

Peixoto, A.L.: RB 322353 (5)

Peixoto, G.L.: 5 (4.1)

Pereira, E.D.M.: 739 (7.1), 4223 (7.1), 4492 (5)

Pereira, F.M.B.: 04/63 (6), 04/134 (4.1), 09/41

(7.1), 24/18 (3), 26/80 (5), 38/60 (5), 40/039

(4.1), 64/139 (3)

Pereira, O.J.: 595 (1.2)

Pessoa, S.V.A.: 303 (1.1)

Pessoal do Horto Florestal: RB 157081 (3)

Pirani, J. R.: 2865 (7.1)

Portella, G.: RB 83996 (5)

Porto, P.C.: 2660 (5)

Quinet, A.: 10/79 (5), 12/85 (5), 23/54 (4.1), 23/89 (5), 28/76 (4.1), 35/81 (5), 35/138 (3), 37/91 (5), 727 (7.1), 736 (2), RB 354532 (3)

Ramalho, A.T.: 25 (5)

Ramos, M.C.L.: 06 (1.1), 134 (1.1), 152 (1.1), 1081 (1.1), RB 328096 (1.1)

Resende, G.S.Z.: 58 (2)
Ribeiro, R.D.: 18 (1.1), 41 (1.1), 44 (7.1), 73 (2), 101 (2), 105 (1.1), 125 (2), 144 (5), 148 (1.1), 153 (5), 230 (7.1), 243 (2), 311 (3), 312 (7.1), 464 (3), 466 (1.1), 471 (4.1), 524 (4.1), 566 (8.1), $594(6), 614(5)$

Riedel, L.: 23 (3), 452 (7.1)

Rosa, P.: 81 (3)

Santos, M.C.F.: 05 (8.1), 445 (3)

Schneider, S.M.: RB 327691 (1.1)

Schwacke: 4750 (4.1), 6363 (7.1)

Silva, L.F.G.: 76 (4.1), 82 (3), RB 81554 (7.1)

Silva, N.S.J.: 10 (4.1), 20 (4.1), 34 (4.1)

Silva, N.T.: RB 330960 (6)

Silveira, O.: 04 (5)

Smith, L.B.: 15351 (3)

Sobrinho, J.P.L.: 102 (7.1), 907 (5), 1153 (7.1)

Spolidoro, M.L.C. V.: 272 (5)

Spruce: 11418 (5)

Sucre, D.: 1317 (2), 1399 (2), 1899 (2), 3159 (2), 4075 (7.1), 4218 (3), 5192 (5), 5367 (7.1), 6091 (7.1), 11084 (4.1), 11311 (2), 11389 (5)

Vaccari: RB 78238 (3)

Vaz, A.F.: 826 (4.1)

Vianna, E.: RB 157813 (4.1)

Vieira, C.M.: 451 (4.1), 462 (4.1)

Yamamoto, K.: UEC 25181

s.c.: RB 157083. 